\title{
Adsorption and decomposition of NOx on Rare Earth
}

\section{Phosphotungstates}

\author{
ZHANG Xueyang $^{1,2,3, a^{*}},{\text { ZHANG } R u^{1, b} \text { and LIU Tianxiang }}^{1, c}$ \\ ${ }^{1}$ School of Environmental Engineering, Xuzhou institute of technology, China \\ 2 Jiangsu Key Laboratory of Environmental Material and Environmental Engineering, China \\ ${ }^{3}$ Key laboratory of Jiangxi Province for Persistant Pollutants Control and Resources Recycle, China \\ azhaxuy@163.com, bsddx2009@163.com, cx xgltx1995@sina.com
}

Keywords: Nitric oxides; Rare earth; Heterpoly acide; Decompositon

Abstract. To reduce NOx emission, $\mathrm{LnPW}$ ( $\mathrm{Ln}=\mathrm{La}, \mathrm{Ce}$, Pr, Nd, Sm, Eu, Gd, Yb, Y; PW= $\mathrm{PW}_{12} \mathrm{O}_{40}$ ) were prepared and used for NOx adsorption and decomposition. The adsorption results showed that NOx adsorption capacity on LnPW were lower than phosphotungstic acid (HPW). After doping with HPW, the NOx adsorption ability of LnPW/HPW was improved significantly. NOx catalytic decomposition on LnPW/HPW was tested by rapid heating, the results showed that catalytic activity of LnPW/HPW was superior to HPW. The effects of doping ratio on NOx adsorption and decomposition were studied on the catalyst of EuPW/HPW, and the results showed that HPW played the role of NOx adsorbent, while EuPW was related to the NOx conversion and $\mathrm{N}_{2}$ selectivity.

\section{Introduction}

Nitrogen oxides $\left(\mathrm{NO}_{\mathrm{x}}\right)$ are considered the primary atmospheric pollutants ${ }^{[1-6]}$. In the last several decades extensive research have been carried out to reduce $\mathrm{NO}_{\mathrm{x}}$ emission, and the $\mathrm{NO}_{\mathrm{x}}$ catalytic decomposition was considered the best method for no reducing agents are consumed ${ }^{[7-12]}$. Numerous experimental investigations have been carried out to look for the $\mathrm{NO}_{\mathrm{x}}$ decomposition catalysts ${ }^{[13]}$. Heteropoly acids (HPAs) attracted much attention due to their acidity, oxidation-reduction and pseudo-liquid phase model. Yang ${ }^{[7]}$ found that phosphotungstic acid (HPW) had the ability to decompose $\mathrm{NO}_{\mathrm{x}}$ to $\mathrm{N}_{2}$ by rapid heating, subsequently, Chen ${ }^{[8]}$, McCormick ${ }^{[14]}$, Zhang ${ }^{[9]}$ and the author ${ }^{[12]}$ reconfirmed the decomposition ability of HPW.

Rare earth has been widely used in catalysis research for its special catalytic performance, and cerium is one of the most used rare earth element in $\mathrm{NO}_{\mathrm{x}}$ deduction, while the others rare earth elements are not investigated sufficiently ${ }^{[15-21]}$. This paper presented the rare earth elements $\mathrm{La}, \mathrm{Ce}, \mathrm{Pr}, \mathrm{Nd}, \mathrm{Sm}, \mathrm{Eu}, \mathrm{Gd}, \mathrm{Yb}$ and kin element $\mathrm{Y}$, and then rare earth phosphotungstates $\mathrm{LnPW}(\mathrm{Ln}=\mathrm{La}, \mathrm{Ce}, \mathrm{Pr}, \mathrm{Nd}, \mathrm{Sm}, \mathrm{Eu}, \mathrm{Gd}, \mathrm{Yb}, \mathrm{Y}$; $\mathrm{PW}=\mathrm{PW}_{12} \mathrm{O}_{40}$ ) which were synthesized by rare earth and $\mathrm{HPW}$ were used to $\mathrm{NO}_{\mathrm{x}}$ adsorption and catalytic decomposition.

\section{Experimental}

Catalyst synthesis. According to the literature ${ }^{[22]}, \mathrm{LnPW}(\mathrm{Ln}=\mathrm{La}, \mathrm{Ce}, \mathrm{Pr}, \mathrm{Nd}, \mathrm{Sm}, \mathrm{Eu}, \mathrm{Gd}, \mathrm{Yb}, \mathrm{Y}$; PW= $\mathrm{PW}_{12} \mathrm{O}_{40}$ ) were prepared by the interaction of $\mathrm{H}_{3} \mathrm{PW}_{12} \mathrm{O}_{40}$ with rare earth nitrate in aqueous solution. $\mathrm{H}_{3} \mathrm{PW}_{12} \mathrm{O}_{40}(3.0 \mathrm{mmol})$ was dissolved in $20 \mathrm{ml} 50 \%$ ethanol solution. To this solution $5 \mathrm{ml}$ rare earth nitrate solution $(3.0 \mathrm{mmol})$ was added dropwise. The mixed solution was gently evaporated to $10 \mathrm{ml}$ in the water bath at $65^{\circ} \mathrm{C}$, and then the crystallization occurred. The crystal was filtrated and dried in vacua at $250{ }^{\circ} \mathrm{C}$ for $2 \mathrm{~h}$. The LnPW were prepared for use. 
Apparatus and gas composition. The schematic diagram of $\mathrm{NO}_{\mathrm{x}}$ adsorption and decomposition reaction equipment was shown in Fig.1. The experiments were conducted in a quartz flow reactor (8 $\mathrm{mm}$ in diameter, with a fritted support) which was equipped with a thermocouple inserted in the catalyst bed. The catalyst was placed in the middle of the reactor between two quartz wool plugs. The feed gas contained 1000 ppm NO which was made by blending $\mathrm{NO} / \mathrm{N}_{2}$ premixed (1.0 vol. \%) with $\mathrm{N}_{2}$ carrier, and other gases such as $\mathrm{O}_{2}(8 \%), \mathrm{H}_{2} \mathrm{O}(5 \%)$ were added also by blending. The blending was accomplished by using a D08-1D/ZM mass flow control blending system (Beijing Seven Star Co. Ltd. Beijing). Water vapor was added by using a heated gas wash bottle. $\mathrm{NO} / \mathrm{NO}_{\mathrm{x}}$ analyzer with a range of 0-2000 ppm (Nanjing Hepu technology Co., Ltd. China) was used to record the effluent $\mathrm{NO}_{\mathrm{x}}$ concentration.

NO $(99.9 \%)$ and high purity grade $\mathrm{N}_{2}, \mathrm{He}, \mathrm{O}_{2}$ were obtained from Xuzhou Huazhong Special Gas Co. Ltd. (Xuzhou, China).

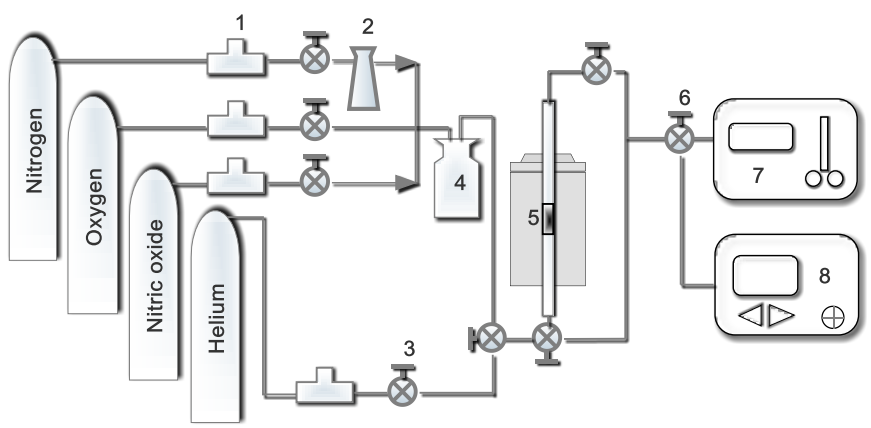

1. Mass flow controller, 2. Water vapor generator, 3. Disconnecting valve, 4. Surge flask, 5. Heating equipment, 6. Three-way valve, 7. Chemiluminescent $\mathrm{NO} / \mathrm{NO}_{2}$ analyzer, 8. Gas chromatography.

Fig. 1 Schematic diagram of NOx adsorption and decomposition reaction equipment

Test procedure. The test procedure comprised a stabilization period of $30 \mathrm{~min}$ in the bypass, for the complete gas mixture. The gas was then allowed to flow through the reactor containing absorbent preheated to $50{ }^{\circ} \mathrm{C}$ and the temperature of oven was increased from $50{ }^{\circ} \mathrm{C}$ to $350{ }^{\circ} \mathrm{C}$ with a temperature ramp rate of $5{ }^{\circ} \mathrm{C} / \mathrm{min}$. The amount of NOx trapped was estimated by an integration of the curve below the baseline (1000 $\mathrm{ppm}$ ) for adsorption, and by expression as $\mathrm{mg} \mathrm{NOx} / \mathrm{g}$.

Decomposition stage: The sample placed in a quartz tube was washed with $20 \mathrm{ml} / \mathrm{min}$ helium for $1 \mathrm{~h}$. Then temperature programmed decomposition was carried out on the catalyst adsorbed NOx. The $\mathrm{N}_{2}$ was detected by gas chromatography with $5 \mathrm{~A}$ molecular sieve chromatography column.

\section{Results and discussion}

NOx adsorption on LnPW. The LnPW were used as sorbents to adsorb 1000 ppm NOx, and the results were shown in Fig.2. All of the rare earth phosphotungstates had the NOx adsorption ability. Among LnPW, GdPW had the highest NOx adsorption efficiency of $81.8 \%$, PrPW was submitted to it with the efficiency of $76.6 \%$, both SmPW and CePW had the efficiency of $72.2 \%$, and the NOx adsorption efficiency of LaPW was $71 \%$ a little higher than NdPW and EuPW, whose NOx removal efficiencies were $63.2 \%$ and $56.8 \%$. Heavy rare earth phosphotungstate YbPW and kin element phosphotungstate YPW had the NOx adsorption efficiencies of $69.3 \%$ and $74.9 \%$, which were similar to light rare earth phosphotungstates. In brief, the NOx adsorption efficiencies of LnPW exhibited the following order: GdPW $>$ PrPW $>$ YPW $>$ SmPW $=$ $\mathrm{CePW}>\mathrm{LaPW}>\mathrm{YbPW}>\mathrm{NdPW}>\mathrm{EuPW}$. 

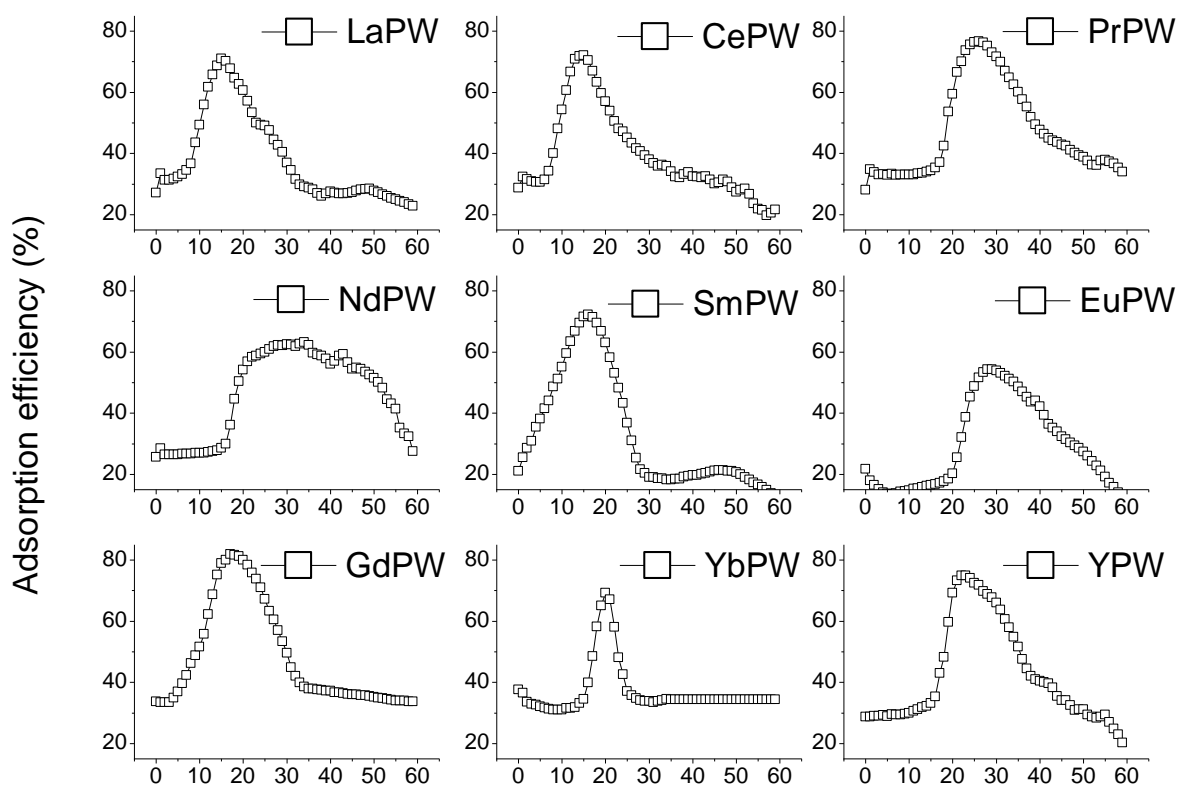

Time (min)

Fig. $2 \mathrm{NO}_{\mathrm{x}}$ adsorption efficiency on LnPW

The NOx adsorption capacities on LnPW were calculated with integral curve, and the results were shown in table 1. The NOx adsorption capacity on LnPW was lower, among them LaPW had the maximum NOx adsorption capacity of $4.34 \mathrm{mg} \mathrm{NOx} / \mathrm{g}$, while EuPW had the minimum NOx adsorption capacity of $2.02 \mathrm{mg}$ NOx/g. The NOx adsorption capacities on LnPW exhibited the following order: $\mathrm{LaPW}>\mathrm{GdPW}>\mathrm{YPW}>$ $\mathrm{PrPW}>\mathrm{CePW}>\mathrm{NdPW}>\mathrm{YbPW}>\mathrm{SmPW}>\mathrm{EuPW}$.

Table 1. NOx adsorption capacity on LnPW

\begin{tabular}{cccccccccc}
\hline Samples & LaPW & CePW & PrPW & NdPW & SmPW & EuPW & GdPW & YbPW & YPW \\
\hline $\begin{array}{c}\text { Adsorption } \\
\begin{array}{c}\text { Capacity } \\
\left(\mathrm{mg} \mathrm{NO}_{\mathrm{x}} / \mathrm{g}\right)\end{array}\end{array}$ & 4.34 & 3.37 & 3.55 & 3.31 & 2.84 & 2.02 & 3.94 & 3.13 & 3.64 \\
\hline
\end{tabular}

NOx adsorption and decomposition on LnPW/HPW. Considering lower $\mathrm{NO}_{\mathrm{x}}$ adsorption ability of pure LnPW, HPW was selected to mix with $\mathrm{LnPW}$, then the doping LnPW/HPW was used as $\mathrm{NO}_{x}$ adsorbent to adsorb $\mathrm{NO}$ at first, then the adsorbed $\mathrm{NO}_{x}$ was catalytic decomposition on LnPW/HPW. The $\mathrm{NO}_{\mathrm{x}}$ adsorption on LnPW/HPW was tested in the following conditions: $\mathrm{NO}_{\mathrm{x}} 1000 \mathrm{ppm}, \mathrm{O}_{2} 8 \%$, water vapor $4.5 \%$, space velocity $10000 \mathrm{~h}^{-1}$ and temperature $200{ }^{\circ} \mathrm{C}$. The adsorption results were shown in Fig.3. After doping with $\mathrm{HPW}$, the $\mathrm{NO}_{\mathrm{x}}$ adsorption on LnPW/HPW was increased obviously, and $\mathrm{NO}_{\mathrm{x}}$ adsorption efficiencies on LnPW/HPW were different from each other. The $\mathrm{NO}_{\mathrm{x}}$ adsorption capacities on LnPW/HPW were calculated with integral curve in $90 \mathrm{~min}$, and the results were shown in table 2. The $\mathrm{NO}_{\mathrm{x}}$ adsorption capacities on LnPW/HPW were higher than those on LnPW, which was because of HPW adsorbing abundant $\mathrm{NO}_{\mathrm{x}}$. 


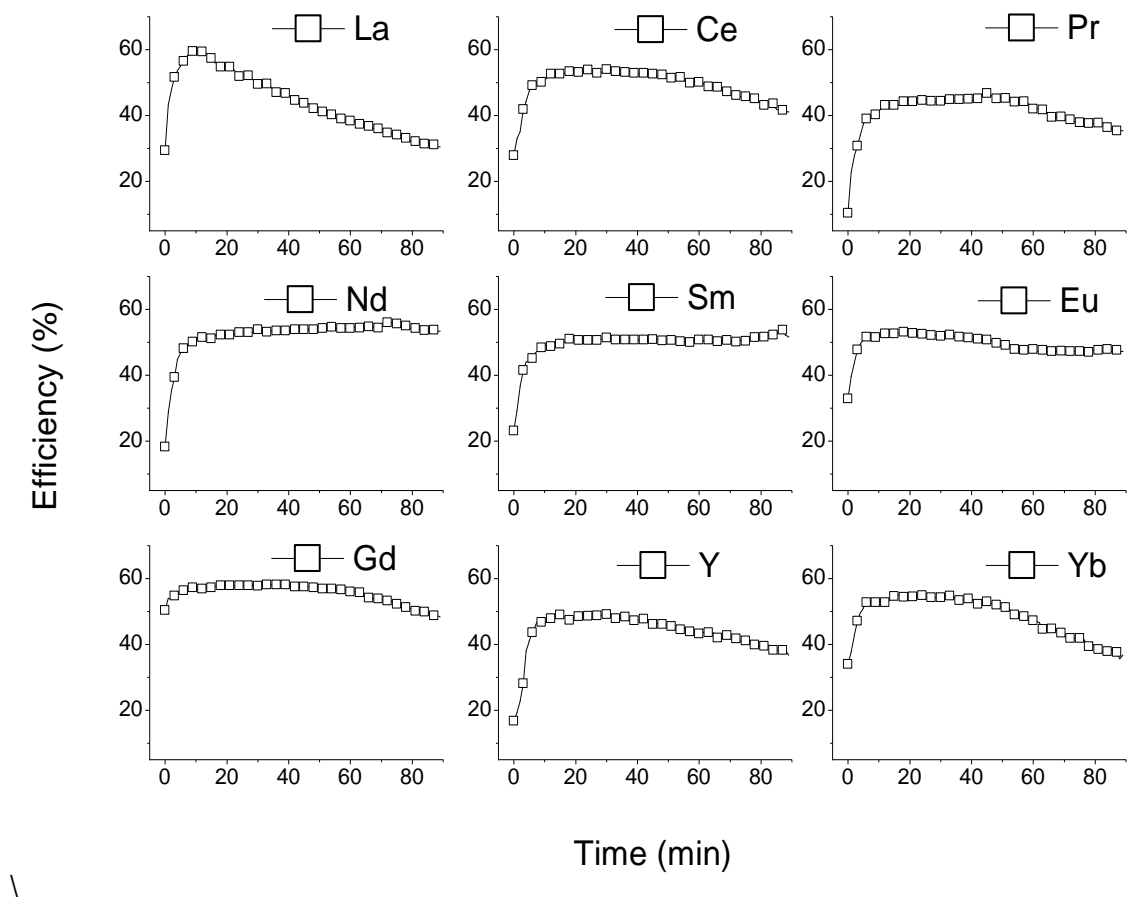

Fig. $3 \mathrm{NO}_{\mathrm{x}}$ adsorption on LnPW/HPW

Electric oven decomposition device was used to investigate the $\mathrm{NO}_{\mathrm{x}}$ decomposition on $\mathrm{LnPW} / \mathrm{HPW}$ adsorbed $\mathrm{NO}_{\mathrm{x}}$. The quartz tube reactor was placed in the oven preheated to $450{ }^{\circ} \mathrm{C}$ with catalyst part being outside, the catalyst part was moved into the oven quickly after washing with helium for $1 \mathrm{~h}$. Sampling probe was used to capture the produced gas, and gas chromatography was used to calculate the $\mathrm{N}_{2}$ production. $\mathrm{NO}_{\mathrm{x}}$ decomposition and $\mathrm{N}_{2}$ yield on LnPW/HPW were shown in table 2. The results showed that the catalytic decomposition of $\mathrm{NO}_{\mathrm{x}}$ on LnPW/HPW were superior to that of HPW. The pure HPW had the $\mathrm{NO}_{\mathrm{x}}$ decomposition efficiency of $4.17 \%$. However, the catalyst of YPW/HPW had the highest $\mathrm{N}_{2}$ yeild of $18.07 \%$, while NdPW/HPW had the lowest $\mathrm{N}_{2}$ yield of $4.84 \%$. In short, the $\mathrm{N}_{2}$ yeild decreased in the order of YPW/HPW >YbPW/HPW > PrPW/HPW > SmPW/HPW > EuPW/HPW > LaPW/HPW > CePW/HPW > GdPW/HPW > NdPW/HPW.

Table 2. $\mathrm{NO}_{\mathrm{x}}$ adsorption and decomposition on LnPW/HPW

\begin{tabular}{llll}
\hline Catalyst & $\mathrm{NO}_{\mathrm{x} \text { adsorption }}(\mathrm{ml})$ & $\mathrm{N}_{2}$ formation $(\mathrm{ml})$ & $\mathrm{N}_{2}$ yield $^{\mathrm{a}}(\%)$ \\
\hline LaPW/HPW & 3.99 & 0.145 & 7.26 \\
CePW/HPW & 4.43 & 0.152 & 6.86 \\
PrPW/HPW & 3.70 & 0.248 & 13.4 \\
NdPW/HPW & 4.72 & 0.114 & 4.84 \\
SmPW/HPW & 4.57 & 0.206 & 9.02 \\
EuPW/HPW & 5.03 & 0.188 & 7.41 \\
GdPW/HPW & 5.01 & 0.169 & 6.74 \\
YbPW/HPW & 4.37 & 0.294 & 13.5 \\
YPW/HPW & 3.94 & 0.356 & 18.1 \\
HPW & 5.42 & 0.113 & 4.17 \\
\hline
\end{tabular}

\footnotetext{
${ }^{\mathrm{a}} \mathrm{N}_{2}$ yeild $=2 \times \mathrm{N}_{2}$ formation $/ \mathrm{NO}_{\mathrm{x} \text { adsorption }}$
} 
Effect of doping ratio on NOx adsorption and decomposition. EuPW/HPW was prepared by mechanical grinding methods, and the mass ratio between EuPW and HPW were 1:9, 1:1 and 9:1. The effect of EuPW/HPW doping ratio on adsorbing NOx was studied in the following conditions: $\mathrm{NOx} 1000 \mathrm{ppm}, \mathrm{O}_{2}$ $8 \%$, water vapor $4.5 \%$ and temperature $150{ }^{\circ} \mathrm{C}$. NOx adsorption results on EuPW/HPW were shown in Fig.4. The effect of doping ratio on maximum NOx adsorption efficiency was unobvious, and all of the three maximum efficiencies were about 55\%. However, the NOx adsorption capacity of EuPW/HPW increased with the improving proportion of HPW, which can be assigned to the possibility that the HPW play the role of NOx sorbent in the catalyst of EuPW/HPW. Thus more HPW in EuPW/HPW would result in more NOx being adsorbed.

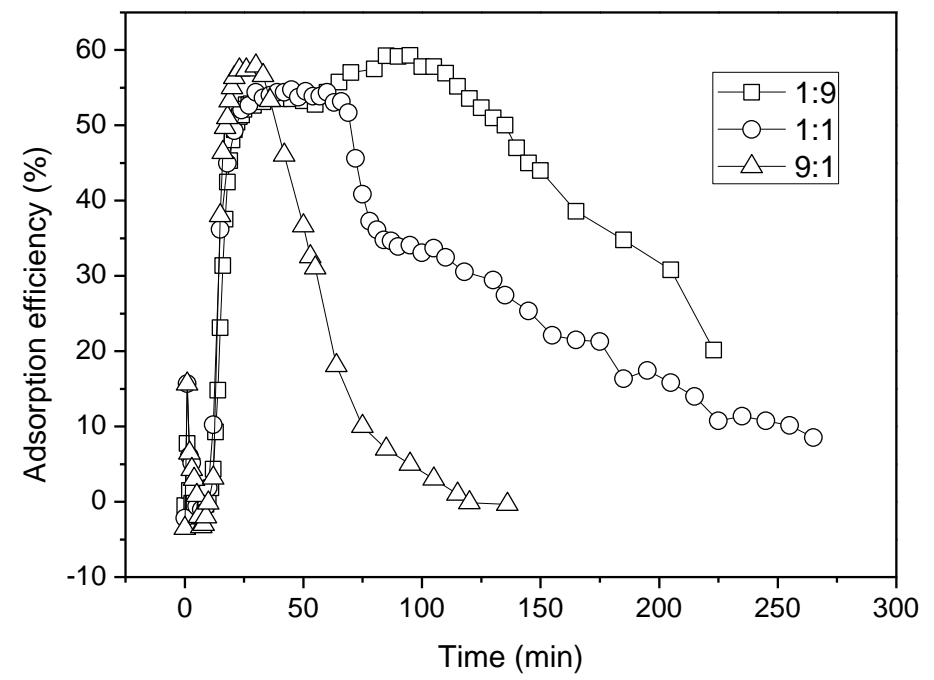

Fig. $4 \mathrm{NO}_{\mathrm{x}}$ adsorption on EuPW/HPW with mass doping ratio of EuPW: $\mathrm{HPW}=1: 9,1: 1$ and 9:1

To investigate the effect of doping ratio on NOx catalytic decomposition, EuPW/HPW with different doping ratio was selected as catalyst. $20 \mathrm{ml} / \mathrm{min}$ helium was used to wash out the $\mathrm{N}_{2}$ and $\mathrm{O}_{2}$ adsorbed in the catalyst for $1 \mathrm{~h}$, then the EuPW/HPW saturated with NOx was rapid heating from $30{ }^{\circ} \mathrm{C}$ to $450{ }^{\circ} \mathrm{C}$ with a temperature ramp rate of $150^{\circ} \mathrm{C} / \mathrm{min}$ by electric oven. $\mathrm{N}_{2}$ produced in the NOx decomposition was detected by Gas chromatograph. The result of doping ratio on NOx decomposition was shown in table $3 . \mathrm{N}_{2}$ yield was $3.9 \%$ when EuPW:HPW $=1: 9$, while the yield was $24.6 \%$ when the ratio increased to 9:1. Thus more EuPW in the catalyst would improve the decomposition of $\mathrm{NOx}$ and the $\mathrm{N}_{2}$ yield, and the active ingredient of EuPW/HPW was rare earth phosphotungstate EuPW.

Table 3. NOx adsorption and decomposition on EuPW/HPW with different doping ratio

\begin{tabular}{ccccc}
\hline EuPW/HPW & Weight $(\mathrm{g})$ & Adsorbed $\mathrm{NO}_{\mathrm{x}}(\mathrm{mg})$ & Production of $\mathrm{N}_{2}(\mathrm{ml})$ & $\mathrm{N}_{2}$ yield $(\%)$ \\
\hline $1: 9$ & 1.2 & 16.3 & 0.40 & 3.9 \\
$1: 1$ & 1.0 & 12.6 & 0.80 & 10.0 \\
$9: 1$ & 1.3 & 4.7 & 0.73 & 24.6 \\
\hline
\end{tabular}

\section{Conclusions}

The following specific conclusions can be drawn from the experimental results. First, the rare earth phosphotungstates had the excellent ability to catalyze decomposition $\mathrm{NO}_{\mathrm{x}}$ into $\mathrm{N}_{2}$. Second, increasing the rare earth phosphotungstates amount on the LnPW/HPW catalyst improved the catalytic performance and $\mathrm{N}_{2}$ formation significantly. 


\section{Acknowledgements}

This work was supported in part by the Natural Science Foundation of the Jiangsu Higher Education Institutions of China (Grant No. 14KJB610010), the Key Laboratory Open Foundation of Persistent Pollutant Control and Resource Recycling of Jiangxi Province (Grant No. ST201422010), the Jiangsu Key Laboratory of Environmental Material and Environmental Engineering and the National Building Materials Industry Science and Technology Innovation Plan (Grant No. 2014-M4-1).

\section{References}

[1] G. François, Mechanism of NOx decomposition, Applied Catalysis A: General, 222 (2001) 183-219. [2] M.A. Gómez-García, V. Pitchon, A. Kiennemann, Pollution by nitrogen oxides: an approach to NOx abatement by using sorbing catalytic materials, Environment International, 31 (2005) 445-467.

[3] Z.M. Liu, S.I. Woo, Recent advances in catalytic deNOx science and technology, Catalysis reviews, 48 (2006) 43-89.

[4] S. Roy, M.S. Hegde, G. Madras, Catalysis for NOx abatement, Applied Energy, 86 (2009) 2283-2297.

[5] K. Skalska, J.S. Miller, S. Ledakowicz, Trends in NOx abatement: A review, Science of The Total Environment, 408 (2010) 3976-3989.

[6] C. Zhu, S. Liu, H. Liu, J. Yang, X. Liu, G. Xu, NOx emission characteristics of fluidized bed combustion in atmospheres rich in oxygen and water vapor for high-nitrogen fuel, Fuel, 139 (2015) 346-355.

[7] R.T. Yang, N. Chen, A New Approach to Decomposition of Nitric Oxide Using Sorbent/Catalyst without Reducing Gas: Use of Heteropoly Compounds, Industrial \& Engineering Chemistry Research, 33 (1994) 825-831.

[8] N. Chen, R.T. Yang, Activation of Nitric Oxide by Heteropoly Compounds: Structure of Nitric-Oxide Linkages in Tungstophosphoric Acid with Keggin Units, Journal of Catalysis, 157 (1995) 76-86.

[9] Z.Z. Liang, Temperature programmed desorption-mass spectrometry study of NO desorption and decomposition by titania supported 12-tungstoposphoric acid, React.Kinet.Catal.Lett., 76 (2002) 93-101. [10] T. Ma, R. Wang, Catalytic decomposition of NOx, Progress in chemistry, 20 (2008) 798-810.

[11] S. Song, T. Ma, Y. Yao, R. Wang, H. Zhao, New catalyst systems of heteropoly compounds as functional material for the adsorption-decomposition of NO_x, Rlhx, (2009).

[12] X.Y. Zhang, L. Cheng, F. Yang, R. Wang, K. Vladimir, NOx Adsorption and Decomposition over $\mathrm{H}_{3} \mathrm{PW}_{12} \mathrm{O}_{40} / \mathrm{CNTs}$ and the Effect of Microwave Irradiation, Chemical Journal of Chinese Universities, 33 (2012) 1818-1826.

[13] E.R.S. Winter, The catalytic decomposition of nitric oxide by metallic oxides, Journal of Catalysis, 22 (1971) 158-170.

[14] R.L. McCormick, S.K. Boonrueng, A.M. Herring, In situ IR and temperature programmed desorption-mass spectrometry study of NO absorption and decomposition by silica supported 12-tungstophosphoric acid, Catalysis Today, 42 (1998) 145-157.

[15] R.D. Peacock, T.J.R. Weakley, Heteropolytungstate complexes of the lanthanide elements. Part I. Preparation and reactions, Journal of the Chemical Society A: Inorganic, Physical, Theoretical, (1971) 1836-1839.

[16] Q. Zhao, R. Han, J. Li, X. Du, J. Wang, Synthesis and crystal structure of a 1D chainlike rare earth coordinated tungstogermenate: $\left[\left(\mathrm{CH}_{3}\right)_{4} \mathrm{~N}\right]_{1.50} \mathrm{H}_{3.50}\left[\mathrm{Gd}\left(\mathrm{GeW}_{11} \mathrm{O}_{39}\right)\left(\mathrm{H}_{2} \mathrm{O}\right)_{2}\right] \cdot 2.5 \mathrm{H}_{2} \mathrm{O}$, Journal of Rare Earths, 27 (2009) 177-181.

[17] L.Z. Zhang, W. Gu, Z. Dong, X. Liu, B. Li, M.L. Liu, Syntheses, structures and properties of a series of photochromic hybrids based on Keggin tungstophosphates, Journal of Solid State Chemistry, 182 (2009) 1040-1044. 
[18] L. Zhang, S.D. Ding, T. Yang, G.C. Zheng, Adsorption behavior of rare earth elements using polyethyleneglycol (phosphomolybdate and tungstate) heteropolyacid sorbents in nitric solution, Hydrometallurgy, 99 (2009) 109-114.

[19] Y. Xu, X. Zhang, H. Li, Y. Qi, G. Lu, S. Li, Promotion effect of lanthanum addition on the catalytic activity of zirconia supported platinum and tungstophosphoric acid catalyst for n-pentane isomerization, Applied Surface Science, 255 (2009) 6504-6507.

[20] J. Wang, H.y. Zhang, Q. Hao, Structure and luminescence properties of self-assembled films of lanthanide-polyoxometalates clusters/silica core-shell particles, Journal of Alloys and Compounds, 485 (2009) 826-830.

[21] J.p. Wang, Q.x. Yan, X.d. Du, X.y. Duan, J.y. Niu, Synthesis, crystal structures and properties of three rare earth substituted germanotungstates: $\mathrm{M} /\left[[\mathrm{alpha}]-\mathrm{GeW}_{11} \mathrm{O}_{39}\right](\mathrm{M}=\mathrm{Nd}, \mathrm{Eu}$, and $\mathrm{Tb})$, Inorganica Chimica Acta, 361 (2008) 2701-2706.

[22] S. Kang, The Preparation and Characterization and Applied Research of Phosphotungstate Catalyst, in, Harbin Engineering University, Harbin, 2007. 